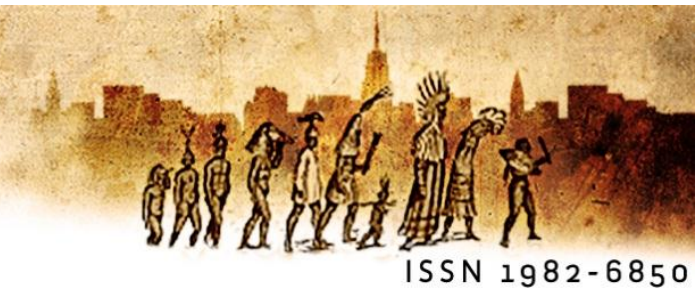

\title{
Para uma avaliação mais objetiva das traduções de poesia*
}

A avaliação de uma tradução de poesia é uma tarefa complexa e delicada. Temos consciência de que o texto poético trabalha com a linguagem em todos os seus níveis semânticos, sintáticos, fonéticos, rítmicos, entre outros. Idealmente, o poema deve articular todos esses níveis, ou pelo menos vários deles, no sentido de chegar a um determinado conjunto harmônico de efeitos poéticos. A tarefa do tradutor de poesia será, pois, a de recriar, utilizando os recursos da língua-meta, os efeitos de sentido e forma do original — ou, ao menos, uma boa parte deles. Meu objetivo no presente trabalho é esboçar uma metodologia para a avaliação da tradução poética, examinando de modo sistemático os diferentes níveis da linguagem envolvidos no poema. Para isso, torna-se necessário definir de modo mais preciso o que queremos dizer quando afirmamos que um determinado elemento de um poema traduzido corresponde a um determinado elemento de um poema original.

Podemos entender o conceito de "correspondência" em diversos níveis de exatidão. Vejamos um exemplo métrico. Digamos que eu queria traduzir para o português um determinado verso inglês com uma pauta acentual que podemos representar como se segue (onde "-" representa uma sílaba átona e "/ " uma sílaba com acento primário, e "|" é o separador de pés):

\footnotetext{
* Agradeço as críticas e sugestões dos professores Márcia A. P. Martins e Victor Hugo Adler Pereira.
}

Eutomia, Recife, 20 (1): 229-245, Dez. 2017 


\section{-||$-||-||--|/|$}

Temos aqui um verso em pentâmetro jâmbico com duas irregularidades: o quarto pé é pirríaco e o quinto é espondaico. Numa primeira acepção da expressão "corresponder", um verso português correspondente a esse verso inglês teria de ser precisamente um

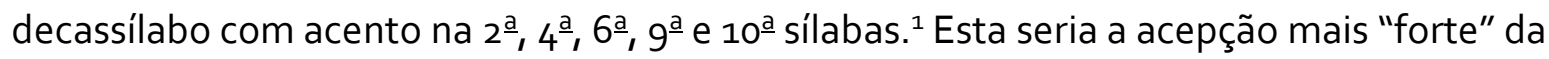
expressão "o verso A corresponde ao verso B", porque se daria no nível mais próximo da realidade fônica do verso. Se enfraquecermos um pouco a acepção de "corresponder", diríamos que qualquer decassílabo de ritmo predominantemente jâmbico no português corresponde a qualquer decassílabo predominantemente jâmbico no inglês. Saltando para um nível ainda mais alto de generalidade, qualquer decassílabo do português corresponderia a qualquer pentâmetro do inglês. Mas podemos ter uma correspondência ainda mais fraca: se considerarmos que o pentâmetro é um metro relativamente longo no inglês - em oposição ao trímetro, por exemplo - e que o decassílabo e o alexandrino no português são metros relativamente longos - em comparação com os hexassílabos e heptassílabos - poderíamos dizer que um alexandrino em português corresponde a um pentâmetro inglês, na medida em que ambos são "versos longos". Podemos esquematizar o que foi dito até agora assim:

\footnotetext{
${ }^{1}$ Há aqui uma simplificação, pois ao pressupormos que um pé jâmbico do inglês corresponde a duas sílabas em português brasileiro não levamos em conta as diferenças entre os sistemas métricos dos dois idiomas, em particular os papéis desempenhados em cada um pela sílaba e pelo acento. Tampouco consideramos o fato importante de que determinados metros do inglês podem corresponder funcionalmente a metros portugueses formalmente diferentes. V., por exemplo, Britto (2000), onde defendo que o metro da balada ingle sa - usado na poesia narrativa popular - tem como melhor equivalente em português a redondilha maior do cordel nordestino.
} 


\begin{tabular}{|l|l|}
\hline$-/|-/|-/|--| / /$ & $-/-/-/--/ /$ \\
\hline pentâmetro jâmbico & decassílabo jâmbico \\
\hline pentâmetro & decassílabo \\
\hline verso longo & verso longo \\
\hline
\end{tabular}

Na primeira linha, temos o caso do sentido mais forte de "correspondência": a um determinado padrão de acentuação no inglês fazemos corresponder uma idêntica configuração de sílabas tônicas e átonas no português. No segundo, temos versos que seguem o mesmo ritmo geral, mas sem a exigência de que as inversões que ocorrem no inglês correspondam ponto a ponto às irregularidades da tradução. No terceiro nível, limitamo-nos a fazer corresponder o número de sílabas; no quarto, trabalhamos apenas com a noção mais vaga de "verso longo" em oposição a "verso curto". Podemos agora entender de modo mais preciso a noção de perda na tradução poética: quanto mais fraca a acepção de correspondência - ou seja, quanto mais alto o nível de generalidade em que ela se dá - maior a perda. No exemplo acima, haverá mais perda se eu traduzir o verso original por um alexandrino do que se eu traduzi-lo por um decassílabo qualquer, por exemplo.

Na avaliação do grau de perda, porém, o nível de generalidade não é o único fator a ser levado em conta. No caso de uma tradução de letra de música, a prosódia musical pede uma correspondência quase exata entre a configuração acentual do original e a da tradução, de modo que mesmo a passagem para o segundo nível de generalidade poderá ser considerada uma perda muito grande. Por outro lado, num poema em verso livre uma correspondência em sentido mais fraco poderá ser perfeitamente aceitável.

Podemos aplicar o mesmo esquema aos outros elementos da forma, e também do conteúdo semântico do poema. É o que veremos na análise de minha tradução do poema "The shampoo", de Elizabeth Bishop. Comecemos com o texto original:2

\section{THE SHAMPOO}

\footnotetext{
${ }^{2}$ Extraído de Bishop (1991).
} 
The still explosions on the rocks,

the lichens, grow

by spreading gray, concentric shocks.

They have arranged

to meet the rings around the moon, although

within our memories they have not changed.

And since the heavens will attend

as long on us,

you've been, dear friend,

precipitate and pragmatical;

and look what happens. For Time is

nothing if not amenable. 
The shooting stars in your black hair

in bright formation

are flocking where,

so straight, so soon?

- Come, let me wash it in this big tin basin,

battered and shiny like the moon.

Examinemos a forma de "The shampoo". O poema tem três estrofes de seis versos. Há uma estrutura rímica bem definida: rimam os versos 1 e 3, 2 e 5, 4 e 6 em cada estrofe. A fórmula da rima é, pois, abacbc, dedfef e ghgihi. Na maioria dos casos a rima é perfeita, mas temos também algumas rimas apenas aproximadas, como as que vemos na segunda estrofe entre os versos 2 e 5 (us - is) e 4 e 6 (pragmatical - amenable), e também na terceira estrofe, entre os versos 2 e 5 (formation - basin). A estrutura rítmica é menos regular que a das rimas, porém não chega a ser de todo livre. Nas três estrofes temos versos mais longos e versos mais curtos. Os longos têm de 4 a 5 pés; sendo o ritmo predominante o jâmbico, isto quer dizer que os versos longos oscilam de 8 a 10 sílabas. Já os versos curtos têm sempre dois pés, o que equivale a quatro sílabas. A distribuição de versos curtos e longos é variável; as únicas constantes são a presença de versos longos nas posições 1, 5 e 6 de cada estrofe; os versos que ocupam a segunda, terceira e quarta posições podem ser longos ou curtos. Podemos resumir as estruturas das estrofes, onde $L$ representa "verso longo" e $C$, "verso curto", na fórmula LCLCLL, LCCLLL e LCCCLL. Todos esses dados são resumidos na primeira tabela do apêndice.

Examinemos a tabela. À esquerda, temos o poema em si, com os acentos primários (/) e secundários ( $(\backslash$ assinalados. Na primeira coluna à direita do texto, temos o esquema de rimas. Na segunda coluna, representamos na linha superior, em itálico, o número de acentos (identificado, para os fins deste trabalho, com o número de pés); e, na inferior, em redondo, o número de sílabas do verso. Na terceira assinalamos se o verso é longo (L) ou curto (C). As duas últimas colunas da tabela resumem elementos ainda não mencionados: na penúltima temos as repetições de fonemas que não se incluem na pauta da rima — no caso, aliterações. Por fim, na última coluna teríamos que listar os elementos semânticos 
do texto, para depois compará-los com os da tradução; porém não haveria espaço na página. Assim, por questões de espaço, vamos nos limitar neste trabalho a examinar mais detidamente apenas os elementos formais do poema. A título de ilustração, examinaremos sob o aspecto semântico os três primeiros versos da primeira estrofe e uma passagem da segunda.

$\mathrm{Na}$ tradução do poema, deveremos tentar preservar aqueles elementos que apresentam maior regularidade no original, já que eles serão possivelmente os mais conspícuos na língua original. Assim, o esquema de rimas - o elemento poético mais regular - deverá ser recriado na tradução. Como a métrica não é rigorosa, pode não ser necessário reproduzir com perfeição a configuração acentual dos versos, mas parece importante conservar a oposição entre versos longos e versos curtos. Quanto às aliterações, elas parecem ser mais significativas na primeira estrofe; na segunda o recurso é pouco utilizado, e ele volta a ganhar importância nos dois últimos versos da terceira estrofe. Por fim, na última coluna ressaltamos um único efeito poético trabalhado no nível do léxico, destacando uma passagem da segunda estrofe em que Bishop se vale de um recurso muito explorado na poesia de língua inglesa: o contraste entre o vocabulário germânico, tipicamente formado por palavras curtas, monossilábicas ou dissilábicas, de significado concreto e conhecidas por qualquer falante, e o vocabulário de origem latina, constituído por termos polissilábicos, abstratos e mais "difíceis". Após três versos onde predominam as palavras germânicas, as palavras latinas "precipitate and pragmatical" se destacam: duras, cheias de oclusivas, semanticamente muito abstratas, totalmente prosaicas; o efeito de humor deste verso é enfatizado pela rima forçada com amenable no final da estrofe. Claramente, esta passagem constitui um efeito calculado da poeta, que seria importante reproduzir no português.

Examinemos agora a tradução do poema: ${ }^{3}$

\section{O BANHO DE XAMPU}

Os líquens - silenciosas explosões

\footnotetext{
${ }^{3}$ Extraída de Bishop (2001).
} 
nas pedras - crescem e engordam, concêntricas, cinzentas concussões.

Têm um encontro marcado

com os halos ao redor da lua, embora

até o momento nada tenha mudado.

E como o céu há de nos dar guarida

enquanto isso não se der,

você há de convir, amiga,

que se precipitou;

e eis no que dá. Porque o Tempo é,

mais que tudo, contemporizador.

No teu cabelo negro brilham estrelas

cadentes, arredias.

Para onde irão elas

tão cedo, resolutas?

- Vem, deixa eu lavá-lo, aqui nesta bacia

amassada e brilhante como a lua.

Examinemos em primeiro lugar os elementos da forma, esquematizados na segunda tabela. ${ }^{4}$ Comecemos com os mais regulares dentre eles. Com relação à rima, foi possível reproduzir o esquema do original, porém com um número bem maior de rimas imperfeitas: em inglês, dos nove pares rimados apenas três não rimam perfeitamente (rimas $e, f$ e $h$ ); no português, pelo contrário, temos apenas dois pares de rimas perfeitas ( $a$ e c). Tentemos medir o grau de perda que ocorreu na tradução das rimas. O que seria o sentido mais forte de "corresponder" no caso da rima? Digamos que seria ter em português o mesmo esquema de rimas, correspondendo a cada rima exata no original uma rima exata

\footnotetext{
${ }^{4}$ Quanto à atribuição de acentos primários e secundários na poesia em português brasileiro, sigo em linhas gerais a orientação de Cavalcanti Proença (1955).

Eutomia, Recife, 20 (1): 226-242, Dez. 2017
} 
na tradução, a cada rima imperfeita uma rima imperfeita, e assim por diante. 5 Neste nível, minha tradução não apresenta correspondência com o original. Portanto, subamos para o nível seguinte de generalidade: apenas o esquema geral é observado; ou seja, o esquema $a b a c b c$, dedfef e ghgihi do original. Aqui, no segundo nível de generalidade, a tradução corresponde de modo bastante fiel ao original. Podemos imaginar uma tradução em que só se tentasse reproduzir as rimas $a$ e $c_{1}$ ou mesmo só a $c_{i}$ teríamos então perdas progressivamente maiores, culminando com uma tradução em versos não rimados.

Podemos resumir essas observações no quadro abaixo, em que a minha tradução corresponde ao segundo nível.

\begin{tabular}{|l|l|}
\hline $\begin{array}{l}a b c a b^{\prime} c \text { ( } a, c: \text { rimas consoantes; b: rima } \\
\text { toante) }\end{array}$ & $\begin{array}{l}a b c a b^{\prime} c \text { ( } a, c: \text { rimas consoantes; b: rima } \\
\text { toante) }\end{array}$ \\
\hline$a b c a b c$ & $a b c a b c$ \\
\hline$a(b) c a(b) c$ & $a b c a d c$ \\
\hline$(a b) c(a b) c$ & $a b c d e c$ \\
\hline$(a b c a b c)$ & $a b c d e f$ \\
\hline
\end{tabular}

Quanto à métrica, já observamos que o original não obedece um padrão estrito, motivo pelo qual não se tentou a correspondência nos três primeiros niveis - a saber, correspondência exata da configuração acentual, correspondência do padrão rítmico geral, e correspondência no número de sílabas. Aqui considerou-se suficiente uma correspondência de quarto nível, que reproduzisse a distribuição de versos longos e versos curtos. Foram utilizados o octossílabo e o decassílabo como versos longos, mas - como no português as palavras tendem a ser mais longas do que no inglês - empregou-se como verso curto o hexassílabo em vez do tetrassílabo. Temos um único verso com mais de 10 sílabas - um hendecassílabo - como penúltimo verso da última estrofe, lugar onde o original aparece também um verso de 11 sílabas. Consegui reproduzir com exatidão a

\footnotetext{
${ }^{5}$ A rigor, o sentido mais forte imaginável de "correspondência" seria a utilização no português dos mesmos sons ocorridos no inglês: assim, a rima $a$, [ $\square \mathrm{ks}]$, teria que reaparecer na posição $a$ em português. Mas como a fonologia do português não é a mesma que a do inglês, essa primeira possibilidade é descartada de saída.
} 
alternância de versos longos e curtos na primeira e na terceira estrofe: LCLCLL e LCCCLL, respectivamente. Apenas na segunda estrofe a correspondência não foi exata: em vez do esquema LCCLLL do original temos na tradução LLLCLL. Temos, pois, uma correspondência razoável no quarto nível, considerado o nível mais baixo relevante para este poema em particular. O diagrama da página 2 resume os diferentes níveis em que se poderia trabalhar o primeiro verso da última estrofe. Podemos repeti-lo aqui:

\begin{tabular}{|l|l|}
\hline$-/|-/|-/|--| / /$ & $-/-/-/--/ /$ \\
\hline pentâmetro jâmbico & decassílabo jâmbico \\
\hline pentâmetro & decassílabo \\
\hline verso longo & verso longo \\
\hline
\end{tabular}

Passemos à terceira coluna do esquema. Aqui não houve nenhuma intenção consciente de reproduzir as aliterações, já que no português a aliteração é recurso muito menos comum do que no inglês; neste quesito seria, portanto, difícil estabelecer níveis de correspondência. Eis um caso em que o tipo de análise aqui proposta encontra dificuldades: o caso em que o recurso poético usado na língua-fonte inexiste - ou existe em grav ou em modo muito diferente - na língua-meta. Também dificulta o cotejo o fato de a aliteração não ser empregada de modo regular e sistemático no original. De qualquer modo, constatei que encontramos na tradução um acúmulo de sibilantes nos três primeiros versos da primeira estrofe, tal como no original, e, nos últimos versos, algumas aliterações em [b], $[s]$ e [l] que de algum modo correspondem às aliterações em [b], [S], [l] do original. Este resultado, é bom ressaltar, foi fruto do acaso ou do inconsciente. Igualmente fortuita foi a concentração de assonâncias em [e] na última estrofe, particularmente no primeiro verso, que não corresponde a nenhum efeito análogo no original. (Podemos encarar estas assonâncias como uma espécie de compensação para as perdas ocorridas nos outros níveis: um efeito criado em português para compensar os que não foi possível recriar a partir do original.) Não tentaremos, pois, estabelecer uma distinção de níveis aqui.

Neste trabalho não examinaremos de modo mais aprofundado os elementos 
sintáticos, semânticos e lexicais. Por considerações de espaço, como já dissemos, vamos apenas esboçar a discussão dos três primeiros versos, e em seguida analisaremos o uso de termos de origem latina na segunda estrofe, mencionado acima. Comecemos com os três versos iniciais:

The still explosions on the rocks, the lichens, grow

by spreading gray, concentric shocks.
Os líquens - silenciosas explosões nas pedras - crescem e engordam, concêntricas, cinzentas concussões.

O nível primeiro de correspondência seria, evidentemente, uma tradução literal, o que raramente é possível em tradução poética. Passando para o nível imediatamente superior, vejamos se o conteúdo lexical do original está ao menos aproximadamente reconstruído na tradução, dando importância maior aos elementos mais centrais substantivos e verbos - depois examinando os adjetivos e advérbios, e analisando por fim a estrutura sintática, a ordenação dos itens lexicais, etc. Nos três versos em questão, os elementos centrais seriam os nomes explosions, rocks, lichens, shocks e os verbos grow e spreading. Em português, teríamos "explosões", "pedras", "líquens", "concussões", "crescem e engordam". A taxa de correspondência é bastante alta; apenas a tradução do verbo spread se afasta da literalidade. Com relação aos adjetivos, teríamos still, gray e concentric traduzidos como "silenciosas", "cinzentas" e "concêntricas", uma correspondência bem próxima à literalidade. Quanto à sintaxe, verificamos que a estrutura do original sofreu uma mudança: se no original The still explosions on the rocks é o sujeito e the lichens é aposto, no português houve uma inversão dessas posições. Por outro lado, a estrutura geral - sujeito, aposto, predicado - foi mantida. Há também uma diferença entre começar o poema com as "explosões" e depois identificá-la como "líquens" e - como está na tradução - primeiro mencionar os "líquens" para depois vê-los como "explosões". Também a sintaxe de grow by spreading foi alterada para "crescem e engordam". Quanto à pontuação, duas das vírgulas foram substituídas por travessões. Podemos dizer, pois, que 
quanto ao aspecto semântico, nos três primeiros versos o grau de correspondência é razoavelmente elevado.

Por fim, vejamos a tradução do recurso semântico do original mais difícil de reproduzir no português: o acúmulo de palavras de origem latina, mais longas, de uso menos comum e pouco eufônicas, na segunda estrofe. Aqui, mais uma vez, seria impossível estabelecer uma correspondência de primeiro nível, pois o português é uma língua de vocabulário predominantemente latino, em que não podemos contrastar palavras nãolatinas com termos latinos. Saltando para o nível imediatamente superior, teríamos não mais o contraste germânico-latino, e sim o que é implicado por ele: o contraste entre vocabulário cotidiano e palavras restritas a um contexto mais formal. Seria esse, talvez, o nível mais baixo de generalidade possível na tradução do inglês para o português; o português nos oferece grandes possibilidades de contraste entre palavras restritas à fala coloquial e outras que só aparecem em contextos formais. No entanto, não consegui encontrar uma solução neste nível de generalidade. O nível seguinte seria talvez contrastar um subconjunto qualquer do léxico com um outro subconjunto diferente. Mas também não foi neste nível que encontrei uma solução. A tradução proposta para esta passagem se situa num nível ainda mais geral, o que considera apenas a categoria genérica de recurso utilizado: a classe de recursos que atuam no nível lexical e não no fonético ou no sintático. Foi neste nível, bem geral, que tentei compensar o recurso não reproduzido com a utilização de dois discretos jogos de palavras: os efeitos de eco entre "dar", "der" e "dá" (1으, $2^{\circ}$ e $5^{\circ}$ versos), e entre "tempo" e "contemporizador" ( $5^{\circ}$ e 6 ํ versos). Temos aqui, talvez, a perda mais séria ocorrida em toda a tradução do poema, na medida em que o nível de generalidade em que foi feita a correspondência é muito alto. Podemos contabilizar também como perda o fato de um efeito conspícuo - a presença de palavras latinas muito pouco eufônicas - ser substituído por algo bem mais sutil - efeitos de eco que talvez só sejam percebidos por leitores atentos. Podemos esquematizar essa discussão na tabela abaixo:

efeito lexical: termos germânicos vs. termos 


\begin{tabular}{|l|l|}
\hline \multicolumn{1}{|c|}{ latinos } & \\
\hline $\begin{array}{l}\text { efeito lexical: vocabulário cotidiano vs. } \\
\text { vocabulário mais rebuscado }\end{array}$ & $\begin{array}{l}\text { efeito lexical: item do português coloquial } \\
\text { vs. } \\
\text { item do português formal }\end{array}$ \\
\hline $\begin{array}{l}\text { efeito lexical: contraste entre dois } \\
\text { subconjuntos }\end{array}$ & $\begin{array}{l}\text { efeito lexical: contraste entre dois } \\
\text { subconjuntos } \\
\text { do léxico }\end{array}$ \\
\hline efeito lexical & efeito lexical: jogo de palavras \\
\hline
\end{tabular}

Tentemos resumir o que foi visto aqui.

Ao avaliar uma tradução, temos que, em primeiro lugar, determinar quais os elementos formais e semânticos do original. Ao comparar cada um deles com sua contraparte na tradução, precisamos utilizar os conceitos antitéticos de "correspondência" e "perda"; quanto maior a correspondência entre um elemento do original e sua contraparte na tradução, menor terá sido a perda. Definimos esses conceitos a partir de uma visão de níveis de correspondência: quanto maior a correspondência ponto a ponto entre os componentes de um dado elemento do original e os componentes de sua contraparte na tradução, menor terá sido a perda. Porém, antes que possamos avaliar o grau de perda, é preciso levar em conta alguns fatores adicionais:

(1) Até que ponto o item em questão é relevante no original? No caso analisado aqui, vimos que a estrutura métrica do original apresenta regularidades, mas não chega a ser rigorosa. Concluímos que a contagem estrita de pés ou sílabas não seria relevante aqui, e que seria suficiente trabalhar com os elementos "verso longo" e "verso curto".

(2) Até que ponto é possível o grau máximo de correspondência? Quando não houver na língua-meta elementos correspondentes aos itens trabalhados no original, a exigência de correspondência terá que ser afrouxada. Foi o que se deu aqui com o contraste estabelecido no original entre vocabulário latino e vocabulário germânico.

(3) Até que ponto uma correspondência exata seria de fato desejável? Pode haver casos em que seja necessário utilizar uma correspondência funcional e não formal. Este 
ponto, que me parece muito importante, não foi discutido aqui. Para um exemplo, remeto o leitor à referência bibliográfica da nota 1 do presente trabalho.

O método proposto é ainda um esboço, em que muitos detalhes ainda precisam ser elaborados. Mas creio que temos aqui um caminho promissor no sentido de chegar a uma avaliação menos subjetivista das traduções poéticas, que trabalhe com dados mais objetivos e permita quantificar os juízos de valor expressos através de conceitos como "correspondência" e "perda". 


\section{Referências}

BISHOP, Elizabeth (1991). The complete poems: 1927-1979. Nova York, Farrar, Straus and Giroux.

(2001). O iceberg imaginário e outros poemas. Seleção, tradução e estudo crítico de Paulo Henriques Britto. São Paulo, Companhia das Letras.

BRITTO, Paulo H. (2000). "Uma forma humilde". Jornal de Resenhas, no 6o, Folha de São Paulo, 11 de março.

CAVALCANTI PROENÇA, M. (1955) Ritmo e poesia. Rio de Janeiro, Organização Simões. 


\section{APÊNDICE}

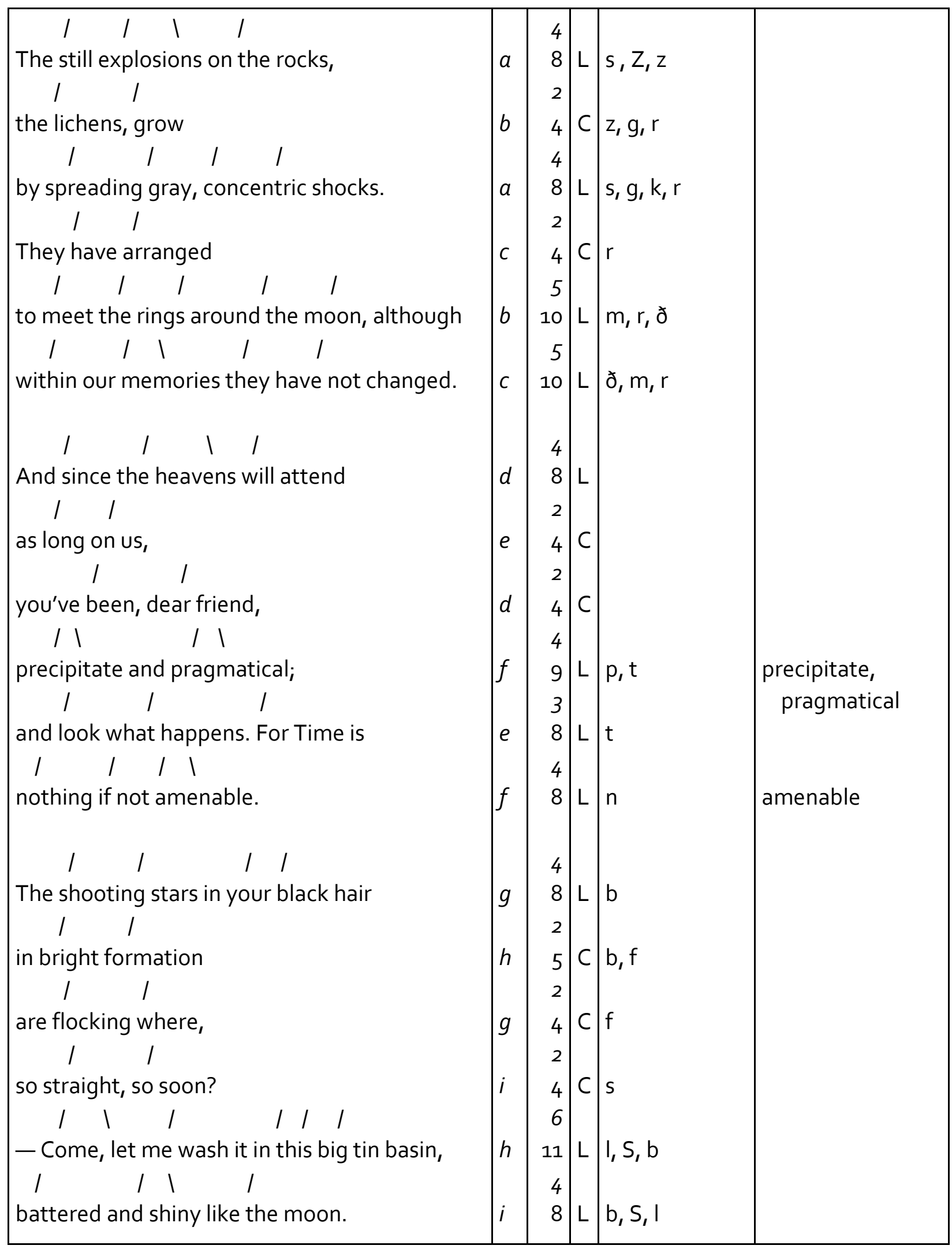




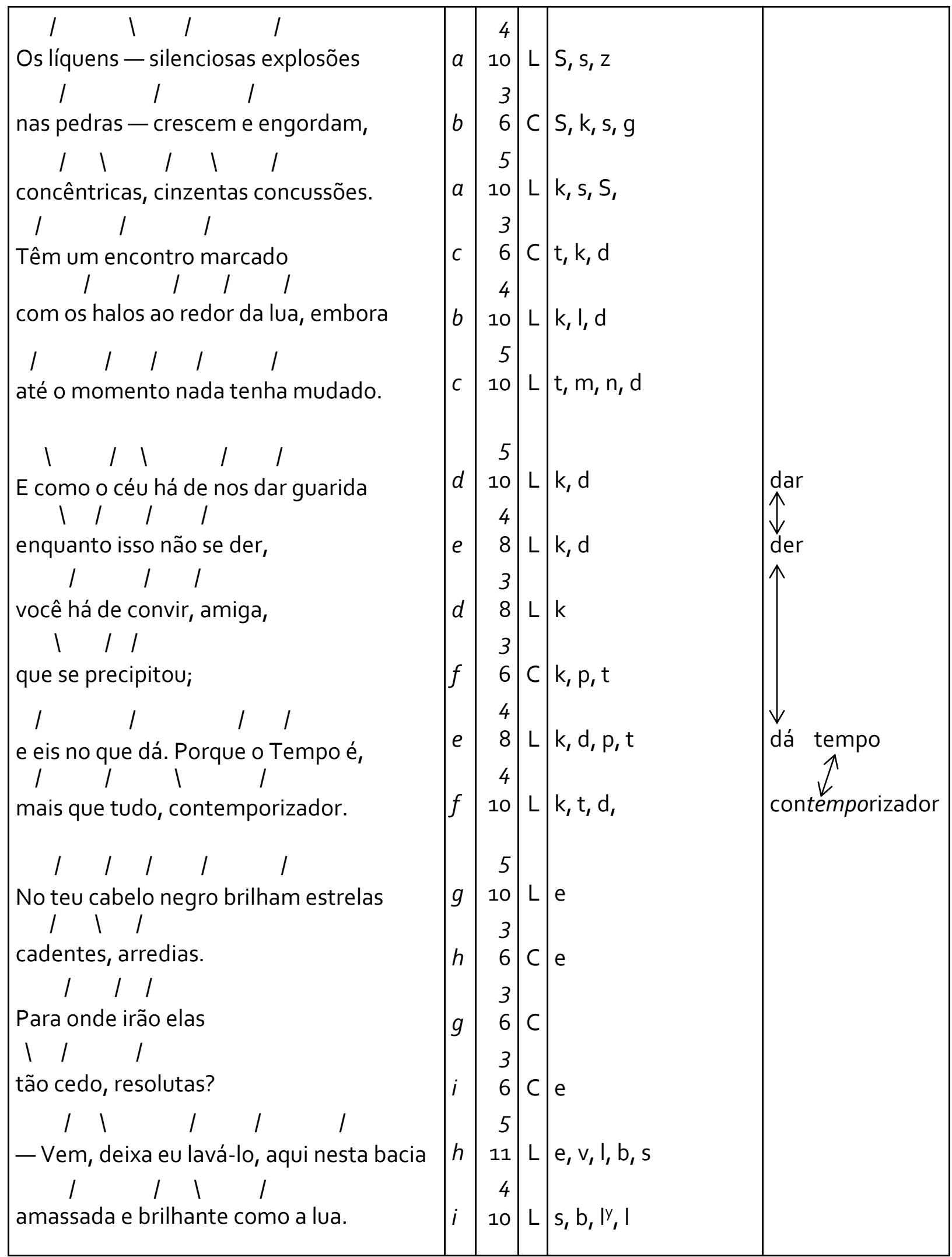


${ }^{\text {i }}$ Paulo Henriques Britto (PUCO-RIO) é Poeta, Contista Tradutor e Professor. 